\title{
Teaching Physics within a Next Generation Science Standards Perspective
}

\author{
Joseph Malcolm Calmer ${ }^{1 *}$ \\ ${ }^{1}$ Hacienda La Puente Unified School District, CA, USA \\ *Corresponding Author: jcalmer@hlpusd.k12.ca.us \\ Citation: Calmer, J. M. (2019). Teaching Physics within a Next Generation Science Standards Perspective. \\ Pedagogical Research, 4(4), em0041. https://doi.org/10.29333/pr/5868
}

Published: August 1, 2019

\begin{abstract}
The Next Generation Science Standards (NGSS) are an explicit document that articulates our pedagogical practices in K-12 science instruction for the United States. The document is an excellent work that describes pedagogy and road maps for building coherence of science principles and student understanding of the Nature of Science. The prescient thing about the current NGSS is that physics teachers have practiced the ideas and tenets prescribed in the NGSS decades ago. Also, the ideas espoused in the NGSS Framework can easily be transferred to other disciplines, especially Math, through specific, articulated lesson building.
\end{abstract}

Keywords: NGSS, standards, science, pedagogy, physics, math

\section{INTRODUCTION}

The Next Generation Science Standards (NGSS) are the framework to guide future instruction in K-12 science classrooms (Bybee, 2013; NGSS Lead States, 2013). The Framework (another term for the NGSS) is the document that explains the rationale for the new standards and the content, practices, and themes of K-12 science instruction in the United States (Committee on Conceptual Framework for the New K-12 Science Education Standards, 2011). The Framework has also drawn heavily on the results and recommendations of PISA (OECD, 2010). Within the Framework, there are extensive descriptions of methodologies of teaching that serendipitously parallels the most, current physics teachers' classroom methodology. One methodology for instruction, or pedagogical practice, could be described as "student centered" (Lewin and Goldstein, 2011). One explanation for these parallels is that physics teachers innately do more tangible activities in the classroom because the concepts are inherently about the physical nature of the world that immediately connects to students more than other courses of study. The ubiquitous practice of demonstrations, having students "do" many of the things they learn about, collect data, think computationally, draw conclusions, develop mental models, and argue from evidence, have been part of physics classrooms since Feynman (Feynman, Leighton, and Sands, 1963). Although these practices have been in the physics classroom, they need to be replicated in and throughout the other science classrooms (maybe even other content areas). In fact, as a physics teacher reads the NGSS Framework, the three dimensions of learning ideas may seem familiar and even validating. The basic tenets of the NGSS are structured in a way to the realization of Principles to Actions (Mathematics, 2014).

\section{WHAT THE PHYSICS CLASSROOM IS}

The foundation of physics instructions is already centered around the daily phenomena that occurs in our students' lives. Physics teachers already have the student engage in (Committee on Integrated STEM Education, National Academy of Engineering, and National Research Council, 2014) minds-on, student-centered activities. 


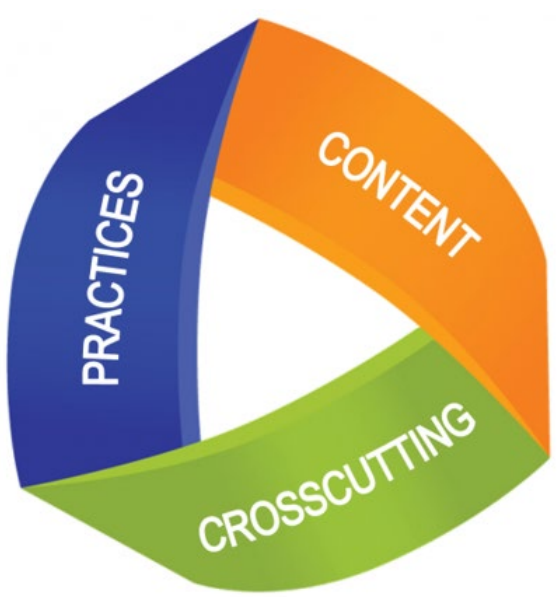

Figure 1. Mobius strip from the NGSS reflecting the 3 Dimensions of Learning

They already have their students interact with equipment and explain phenomena. The Framework envisions a science class where students explain phenomena through speaking, explicit actions, and modeling (Committee on Conceptual Framework for the New K-12 Science Education Standards, 2011). Physics classrooms often have teachers have their students engage with light, colliding objects, moving objects, information transfers, etc.; essentially the entire physics curriculum is about investigating and exploring phenomena (Feynman, Leighton, and Sands, 1965). Arnold Arons poignantly stated that physics teachers need to increase phenomenological thinking in their students to continue to construct their mental understanding of these concepts (Arons, 1997). This means that students need to think about their surroundings or a phenomenon and be able to explain it with insight and evidence. The NGSS is a way for all of the sciences to approach current physic pedagogy from a phenomenological perspective. It describes progressions in science teaching and emphasizing three-dimensional learning (Krajcik, Codere, Dahsah, Bayer, and Mun, 2014).

\section{NGSS STRUCTURAL CHANGE}

The NGSS standards are different from the previous states' standards. The structure of the NGSS is different. This document will only cover the structure in a cursory fashion. There are many other resources that explain these changes in detail (Bybee, 2013; Krajcik et al., 2014).

One way to represent the new standards is by this is the Mobius strip. The three different factions represent the three equal portions of a standard: Science and engineering practices (SEP), Cross cutting concepts (CCC), and Disciplinary Core Ideas (DCI). The academic foundations of these three facets come from the last decade of research that have been generated about learning (Bybee, 1997, 2010; Donovan and Bransford, 2004; Hattie and Yates, 2013; Lidar et al., 2006; Mayer, 2011; Stone, 2007). The Mobius strip is used as a representation of the NGSS framework because thoses tenets are continuously approached and revisited throughout students' K-12 instruction.

To me, it is about making the tacit explicit (Loughran, 2006). In our classrooms, our physics students were required to question, think, explain, and argue like scientists, but it was only tacitly the science standard. Now it is explicitly the standard. The SEPs will feel natural to us, physics teachers. They are the praxis that we have already been doing, but on an individual basis only, it was not systematic.

\section{CHANGES IN SCIENCE TEACHING: PROGRESSIONS AND COHERENCE}

A unique aspect about the NGSS is that the standards are really designed for progression of knowledge over a students' lifetime in K-12 education, with the intent of College and Career readiness. The immediate benefit of this is that students will have exposure to science earlier and more consistently. Along with a progression, there is also the opportunity integration of the Mathematics and ELA standards from the Common Core (in the "connection boxes"). The current drawback is that we will not see the effects of these practices for many years. There is an immediate shift of reliance towards primary education to introduce topics that will be expanded upon later; as a student progresses through their education.

The ultimate goal is coherence. Anyone who has watched a Richard Feynman talk or read one of the books about him, can vouch for his eloquence and his coherent view of the world (O’Brien, 2015). Coherence is built over time and is the ultimate goal of science education. It is created through years of explanations (some right and changing those that are wrong). Those explanations of phenomena occur with practice. The NGSS tries to make 


\section{Crosscutting Concepts}

Patterns

Cause and effect

Scale, proportion, and quantity

Systems and system models

Energy and matter

Structure and function

Stability and change

Figure 2. List of Crosscutting Concepts

all science courses have the same outcome as our physics courses: a comprehension of how observable phenomena work. Physics teachers often talk about and explain phenomena, now all science teachers will have to require their students to explicitly explore phenomena, not just tacitly or theoretically, but practically.

\section{CROSS CUTTING CONCEPTS IN PHYSICS}

One way to explore phenomena and see the world coherently is through the CCC. As you can see, all of these concepts are in physics; every topic can be covered through this list. The NGSS authors listed these as items that span all of science.

I know we all see and feel the familiarity with the items on the list in Figure 2. I am sure we are thinking about specific subject matter that would fulfill the requirements of each of these. For example, in Circuits, we teach about the structure of a circuit, which would enable its function, but the problem was that these concepts were not made explicitly to students, at least not on a generalizable or systemic scale. Despite our tacit understanding of these items, we need to make these explicit to our students. Now all science courses at all levels need to make the tacit explicit. In the new standards and the performance expectations, the CCC is the green box in the NGSS.

As a person who has trained others and read the Framework, I think that the CCC is the place to start. We need to have these ubiquitous concepts start to percolate our learning objectives. Some educational researchers are starting with the SEPs, fortuitously most physics teachers' practices already tacitly work with the SEPs (Bybee, 2011b). I think that the CCC will give us the most benefit for our transition into the NGSS. For example:

- A pattern that is observed in physics is collisions. Their behavior can be predicted because it's a "pattern".

- I think we can all agree that Newton's Laws articulate "cause and effect"

- Vectors can represent "Scale, Proportion, and Quantity"

- An example of "systems" and "energy" exists in Thermodynamics

- A circuit has needs a certain "structure to function" and "stability and change" can be used for conservation of energy or momentum or through any investigation, really.

These are cursory examples and I am sure once you start looking at them and planning, you'll see better ways to acclimate them into your teaching. A great place to build your foundation of a new physics direction is with the Crosscutting Concepts. To me, the best way to reach physics novices is by using these 7 ideas as a frame for the concepts to be learned. 


\section{SCIENCE AND ENGINEERING PRACTICES}

Another change in the standards is the "Science and Engineering Practices". These are a list of eight practices that scientists and engineers have been identified to do in the course of their work. They are "ask questions and define problems", "develop and use models", "plan and carry out investigations", "use math and computational thinking", "analyze and interpret data", "construct explanations and design solutions", "engage in argumentation", and "obtain and evaluate evidence" (NGSS Lead States, 2013). From the physics classrooms I've taught and observed, these are practices that all physics teachers have expected of their students, but have not actually clearly articulated them as the standard. These items (or SEPs) were sort of tacit understandings presented by the teacher and loosely demonstrated by lab work or projects. Now the explicit expectation is that students will do these SEPs through their exploration into physics and other sciences' concepts and curricula.

\section{PERFORMANCE EXPECTATIONS AS DEMONSTRATIONS OF KNOWLEDGE}

Here is a sample Performance Expectation (PE) for students in high school. The PE HS-PS.4-1 states: "Using mathematical representations to support a claim regarding relationships among frequency, wavelength, and speed of waves traveling in various media" (NGSS Lead States, 2013). All high school physics teachers have done this, in varying capacities, in their high school physics classrooms. The question is, "how will I teach this now?" The answer would be, from me, the same way, only extended to incorporate the CCC and SEPs explicitly.

You can use the ripple tanks and make your wave machines like before; because they're proven to work for teaching physics. The difference now is that students ought to generate their own questions to test their science apparatus. For example, students can ask, does the amplitude of the wave diminish over time or length of the apparatus? Then they can ask "why". There are many pathways that the students' questions could go. Is there a difference of wave speed from air, liquid, or solids? The base point is that content (DCI), practices (SEP), and themes (CCC) are all tantamount in the Performance Expectations of students. Now the standard makes that pedagogical model explicit. Not only do students need to learn about waves, but how to support their claims with evidence.

Basically, Students have to generate their questions to research and gather data. When students begin to think like scientists, arguably they are learning more because they are interacting and experiencing more (Dewey, 2007). When students ask their own questions, research states that students are more motivated in the learning cycle (Bransford et al., 1999; Pink, 2011).

\section{Science as Storytelling}

There is a new concept emerging as a pedagogical tool for science teaching. It is called "storytelling". Essentially it is akin to what Feynman does in the YouTube video described above or Neil deGrasse Tyson in his podcasts and TV shows; it is explaining the deep science concepts through a story. One method of doing this is looking for and engaging students through "phenomena". I know all physics classrooms use demonstrations and labs. The NGSS emphasis is on making the demonstration (the phenomena) a driving force for the unit of study. A quick Google search of "NGSS Phenomena" will yield a lot of results. There are twitter accounts devoted to sharing phenomena with other teachers. For example, John Speigel (@sdngss) has promoted a movement called "Project Phenomena" which is dedicated to sharing phenomena for classroom use.

To me, and to other physics teachers, there would be a natural affinity for the structure and intention of the NGSS. The NGSS has an unusual format that has some getting used to, since it is so radically different than the previous standards. However, the essence of the new standards is tacitly and deeply rooted to what Arons and others have already defined as good physics teaching (Arons, 1992; Knight, 2002).

\section{CONCLUSION}

Ultimately, when a Physics Teacher reads the Framework and continues to learn about the NGSS, they will see it as a validation of physics pedagogy that has always occurred. The common denominator for physic instruction is that it requires students to engage and reflect on phenomena and the nature of one's world. The NGSS has tried making the practices of physics teachers replicable to all of the other science courses. Physics teachers have always used phenomena and talked about the interconnectedness of physics concepts to the other sciences. The conclusion is that all science learning needs to adapt some of the practices of typical physics pedagogy. The NGSS is an attempt to describe how students ought to learn science in their science classrooms; arguably it is done in physics, but it should be practiced in all the sciences and beyond (Bybee, 1997). 
The NGSS has used some concepts that we learned from research about student learning (Bransford et al., 1999; Hattie and Yates, 2013). There are many notions of teaching practices that are tacit expectations of science teachers for their students. We want students to learn the content, but we also want then to see the patterns, the cause/effects, structure/ functions, etc. and we want them to learn the concepts by asking questions, analyzing data, etc. Ensuring that students are active in their learning are ideas that are posited by many and demonstrated to work (Bybee, 2011a; Graham and Lesseig, 2019; Zager, 2017). However, these notions of teaching were never explicit and tantamount to content in the standards prior to the NGSS. They are now explicit. The NGSS is an attempt to make the tacit explicit for students.

In conclusion, teaching physics, as any physics teacher knows, is a great experience. It is the most unique and engaging course I've taught. Also, I have experienced the most success of student learning in physics. There is something unique about physics and physics teaching. Students can make connections and experience things that are not always done in other classes or sciences. The NGSS is a great document that has articulated the best practices of physics teaching and made them available to all science teachers. Also, the NGSS is a chance for us to bring more creativity in one's lessons. The standards are multifaceted, intricate, and complex. This is a great opportunity to reflect and increase your creative nature. Sources like Invitations to Science Inquiry is a great place to start amending your teaching practice; while continuing to absorb more as a professional learner (Liem, 1987).

\section{REFERENCES}

Arons, A. B. (1992). Teachers of physics in our schools. American Journal of Physics, 60(2), 103. https://doi.org/10.1119/1.16973

Arons, A. B. (1997). Teaching introductory physics. New York: Wiley. https://doi.org/10.1063/1.881810

Bybee, R. W. (1997). Achieving scientific literacy: from purposes to practices. Portsmouth, NH: Heinemann.

Bybee, R. W. (2010). What Is STEM Education? Science, 329(5995), 996. https://doi.org/10.1126/science.1194998

Bybee, R. W. (2011a). Inquiry is essential. Science and Children, 48(7), 8.

Bybee, R. W. (2011b). Scientific and Engineering Practices in K-12 Classrooms: Understanding "A Framework for K-12 Science Education". Science and Children, 49(4), 10.

Bybee, R. W. (2013). Translating the NGSS for Classroom Instruction. Arlington, VA: NSTA Press.

Committee on Conceptual Framework for the New K-12 Science Education Standards. (2011). A Framework for K12 Science Education: Practices, Crosscutting Concepts, and Core Ideas. Washington, DC: The National Academies Press.

Committee on Integrated STEM Education, National Academy of Engineering, \& National Research Council. (2014). Integration in K-12 STEM Education: Status, Prospects, and an Agenda for Research. Washington: National Academies Press.

Dewey, J. (2007). Experience and Education. Free Press.

Donovan, S. and Bransford, J. (2004). How Students Learn: Science in the Classroom. National Academies Press.

Donovan, S., Bransford, J. D. and Pellegrino, J. W. (Ed.) (1999). How people learn: bridging research and practice. Washington, DC: National Academy Press.

Feynman, R. P., Leighton, R. B. and Sands, M. (1963). The Feynman lectures on physics. Addison-Wesley Pub. Co.

Feynman, R. P., Leighton, R. B. and Sands, M. (1965). The Feynman Lectures on Physics; Vol. I. American Journal of Physics, 33(9), 750-752. https://doi.org/10.1119/1.1972241

Graham, M. and Lesseig, K. (2019). Back-Pocket Strategies for Aurgumentation. Mathmatics Teacher, 112(3), 173178. https://doi.org/10.5951/mathteacher.112.3.0172

Hattie, J. and Yates, G. C. R. (2013). Visible Learning and the Science of How we Learn (pp. 368). https://doi.org/10.4324/9781315885025

Knight, R. D. (2002). Five Easy Lessons: Strategies for Successful Physics Teaching. Addison Wesley.

Krajcik, J., Codere, S., Dahsah, C., Bayer, R. and Mun, K. (2014). Planning Instruction to Meet the Intent of the Next Generation Science Standards. Journal of Science Teacher Education, 25(2), 157. https://doi.org/10.1007/s10972-014-9383-2

Lewin, W. H. G. and Goldstein, W. (2011). For the love of physics: from the end of the rainbow to the edge of time-- a journey through the wonders of physics (Vol. 1st Free Press hardcover). New York: Free Press.

Lidar, M., Lundqvist, E., Östman, L., Utbildningsvetenskapliga, f., Institutionen för, l. and Uppsala, u. (2006). Teaching and learning in the science classroom: The interplay between teachers' epistemological moves and students' practical epistemology. Science Education, 90(1), 148-163. https:/ / doi.org/10.1002/sce.20092

Liem, T. L. (1987). Invitations to Science Inquiry. Ginn Press.

Loughran, J. (2006). Developing a Pedagogy of Teacher Education (Kindle Edition ed.). New York: Routledge. 
Mathematics, N. C. o. T. o. (2014). Principles to Actions: Ensuring Mathematical Success for All. NCTM, National Council of Teachers of Mathematics.

Mayer, R. E. (2011). Applying the Science of Learning. Boston, MA: Pearson Education.

NGSS Lead States. (2013). Next Generation Science Standards: For States, By States. Washington, D.C.: Achieve, Inc. on behalf of the twenty-six states and partners that collaborated on the NGSS. Available at: http://www.nextgenscience.org/next-generation-science-standards

O’Brien, M. (Producer). (2015, 11/22/2015). Richard Feynman: Fun to Imagine. Fun to Imagine Collection. Available at: https:/ / www.youtube.com/watch?v=GqvggMpJgL0

OECD. (2010). PIS A 2009 Results: What Students Know and Can Do - Student Performance in Reading, Mathematics and Science (Volume 1), 276 p. https://doi.org/10.1787/9789264091450-en

Pink, D. H. (2011). Drive: the surprising truth about what motivates us (Vol. First Riverhead trade pbk.). New York: Riverhead Books.

Stone, R. (2007). Best practices for teaching science: what award-winning classroom teachers do? Thousand Oaks, CA: Corwin Press.

Zager, T. (2017). Becoming the Math Teacher You Wish You'd Had: Ideas and Strategies from Vibrant Classrooms. Stenhouse Publishers. 